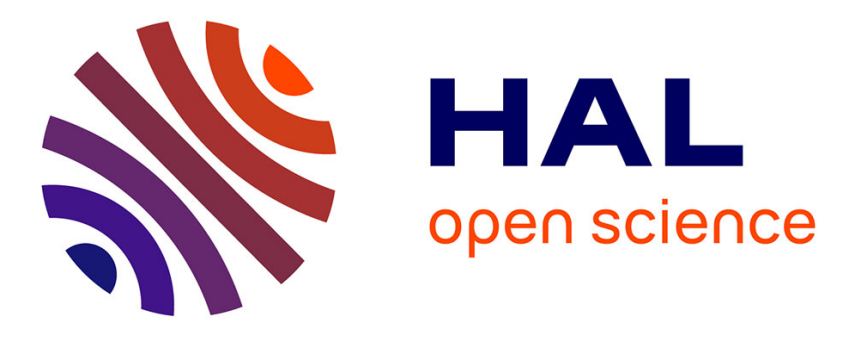

\title{
Radicalar probes to measure the action of energy on granular materials
}

Michel Baron, Alain Chamayou, L Marchioro, J Raffi

\section{To cite this version:}

Michel Baron, Alain Chamayou, L Marchioro, J Raffi. Radicalar probes to measure the action of energy on granular materials. Advanced Powder Technology, 2005, 16 (3), p.199-211. $10.1163 / 1568552053750242$. hal-01632795

\section{HAL Id: hal-01632795 \\ https://hal.science/hal-01632795}

Submitted on 8 Nov 2019

HAL is a multi-disciplinary open access archive for the deposit and dissemination of scientific research documents, whether they are published or not. The documents may come from teaching and research institutions in France or abroad, or from public or private research centers.
L'archive ouverte pluridisciplinaire HAL, est destinée au dépôt et à la diffusion de documents scientifiques de niveau recherche, publiés ou non, émanant des établissements d'enseignement et de recherche français ou étrangers, des laboratoires publics ou privés. 


\title{
Radicalar probes to measure the action of energy on granular materials
}

\author{
M. BARON ${ }^{1, *}$, A. CHAMAYOU ${ }^{1}$, L. MARCHIORO $^{1}$ and J. RAFFI ${ }^{2}$ \\ ${ }^{1}$ Chemical Engineering Laboratory for Particulate Solids, UMR CNRS 2392, École des Mines \\ d'Albi-Carmaux, 81013 Albi CT Cedex 09, France \\ ${ }^{2}$ Laboratory of Radiolysis of Organic Matter, UMR CNRS 6171 and CEA, Faculté des Sciences de \\ Saint-Jérôme, 13397 Marseille Cedex 20, France
}

\begin{abstract}
Measuring the action of energy on matter is a complex problem, especially in the case of granular materials. For example, particle size reduction by grinding generally shows poor overall energetic yields and a significant challenge in this area is to accurately estimate the energy consumed, including that stored in the particles. Fine or ultra-fine grinding processes require a lot of energy, part of which becomes internal energy and can lead to mechanochemical reactions and useful products. We studied the appearance of free radicals during the grinding of $\alpha$-lactose monohydrate by means of electron spin resonance (ESR). These radicals are the same as those induced by $\gamma$-radiation and comparison of ESR spectra intensities with those from ground products allows the determination of an 'equivalent $\gamma$-irradiation dose'. This gives a novel concept for characterizing the action of mechanical energy on matter in fine grinding by using molecular probes. This is the first example of the investigation of mechanochemical energy during the fine grinding process.
\end{abstract}

Keywords: Electron spin resonance; mechanochemical radical; fine grinding; lactose; $\gamma$-irradiation; molecular probe.

\section{NOMENCLATURE}

$\Delta H \quad$ hyperfine constant, for multiplet ESR signals

$g_{\text {factor }}$

a way to measure the center of the ESR spectrum

$Y_{\mathrm{R}}$

ratio of the 'quantity of energy used in the lactose sample to induce chemical reactions and radicals' divided by the 'total quantity of energy used by the $\gamma$-cell during irradiation treatment'

\footnotetext{
*To whom correspondence should be addressed. E-mail: Michel.Baron@enstimac.fr
} 
ratio of the "quantity of energy used in the lactose sample to induce chemical reactions and radicals' divided by the 'total quantity of energy used by the mill during grinding treatment'

\section{INTRODUCTION}

An important challenge remaining in the area of grinding science is to accurately estimate the efficiency of energy consumption. Mechanochemical products can appear during fine or ultra-fine grinding. To achieve this state requires a lot of energy and therefore the mechanochemical reaction energy can be assumed to be the grinding energy [1]. In some cases, mechanochemical phenomena can be observed by electron spin resonance (ESR) spectroscopy. In this paper, we use the example of lactose grinding. Free radical production from $\alpha$-lactose monohydrate has been studied using ESR in order to examine the energy efficiency as accurately as possible. The calibration problem was solved by comparison of lactose samples treated either by mechanical stress or $\gamma$-irradiation [2].

Grinding operations generally show poor energetic yields. It is generally recognized that only $5 \%$ or less is used for effective fragmentation, because of many losses through increasing temperature, mechanical and electric losses, etc. Rumpf [3] described the many phenomena occurring during grinding operations. In the case of fine or ultra-fine grinding $(0.1 \mathrm{~mm}$ to $1 \mu \mathrm{m}$ or even $1 \mathrm{~nm})$, these phenomena are reinforced, because fine grinding needs more energy than coarse grinding [1]. Also, it becomes more and more important for economical, energetical and environmental reasons to have a good knowledge of the effective energy needed at the grain, crystal or molecular level during grinding. Many research projects are in progress to characterize the complex phenomena taking place during the fracture process. However, intimate knowledge of the behavior of matter and energy at the molecular level requires the use of new methods able to explore granular material at this molecular level.

Effectively, during treatments of powders, it is generally not possible to accurately determine the energy actually used during the transformation:

- The energy may produce different side-effects (e.g. heating during grinding).

- The total energy given may be known, but not the absorbed energy (e.g. the general case of UV radiation).

However, in case of $\gamma$-irradiation, the absorbed energy is generally well known as it is easily measured by different dosimetry techniques such as ESR [4, 5].

During a grinding operation, it is generally recognized that the behavior of material can change from a brittle to a ductile one, even if sometimes the behavior is in fact more complex and partly visco-elastic. Generally, the fragmentation of a solid is initiated by applying a constraint or constraint field generating deformations in the volume of the material. If enough energy is brought at the grain level, the elastic behavior stops, a crack appears and breakage occurs. If grinding creates 


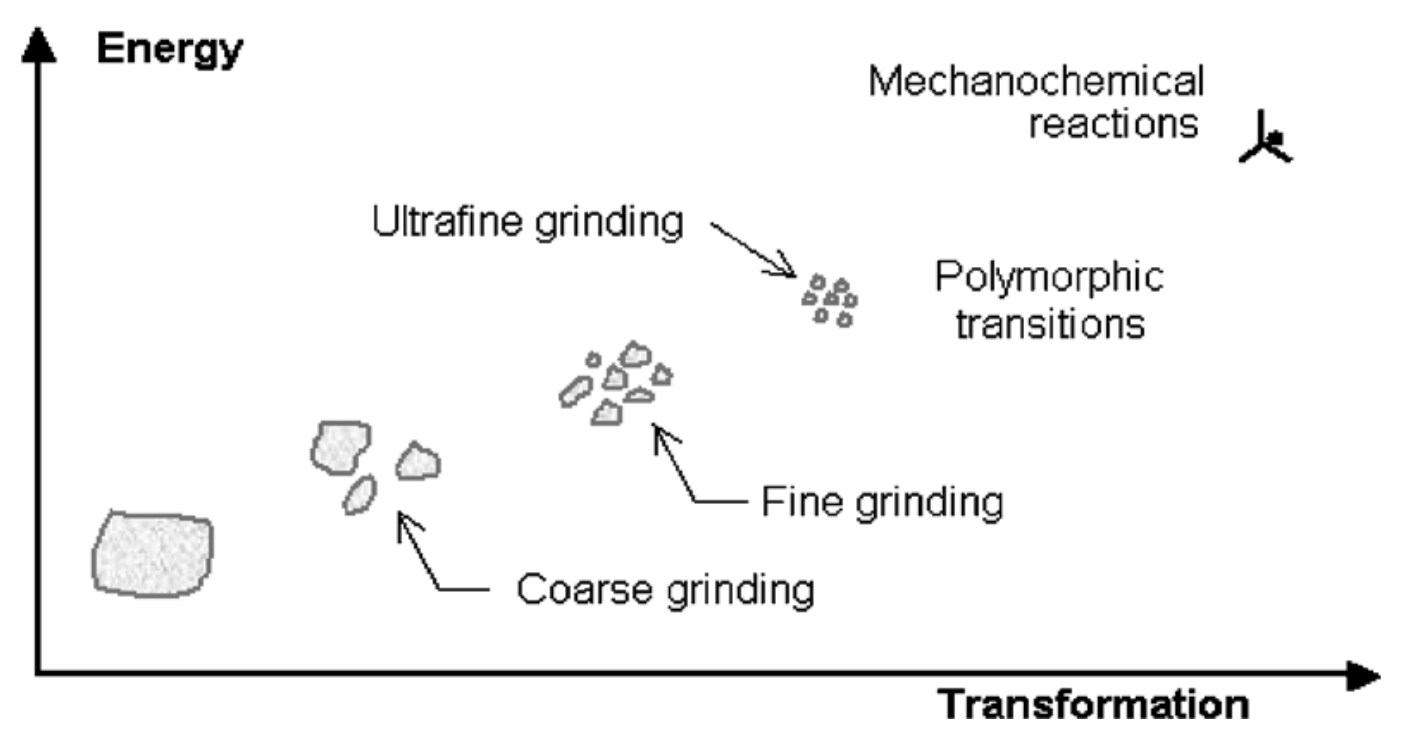

Figure 1. Symbolic representation of the relative energy levels required for different mechanochemical transformations.

fractures at the particle, crystal or molecular level, grinding induces an out-ofequilibrium state and creates many defects in the material. These defects can appear at the surface of the particles, in a thickness of some micrometers, but can also appear in the volume by diffusion, displacement of the dislocations and vacant sites.

The plastic deformation and the disorganization of the crystalline network induces an energetically activated state, more reactive, by mechanical activation. The main result of mechanical activation is not only the increase of the specific surface of the solid, but also the accumulation of defects, modifying the reactivity of the whole solid. As a result, an unstable level is obtained and chemical reactions can be the result of this mechanical activation. These mechanochemical reactions can produce molecular entities different from those obtained by thermal mechanisms.

The level of energy needed to perform mechanochemical reactions is similar to the energy used for ultra-fine grinding [1]. Figure 1 shows a symbolic representation of the level of energy needed for grinding and mechanochemical transformations. During a previous joint work between Ecole des Mines d'Albi and LRMO [2], we observed that some stable radicals were created by mechanochemical transformation during the grinding of $\alpha$-lactose monohydrate using a vibratory mill. Because these radicals showed good stability in the ground powder, we envisaged the possibility of using the radicals produced in the powder as a probe in order to investigate, at the molecular level, the amount of energy used during a mechanochemical reaction.

\section{MATERIALS AND METHOD}

All the ESR spectra were recorded with a Bruker EMS 104 spectrometer especially built for dosimetric measurements [5].

Irradiations of $\alpha$-lactose monohydrate (Granulac 70, fine milled lactose, conforming with the European Pharmacopeia, USP/NF and JP, from Meggle, Germany) were performed at room temperature in the ${ }^{60} \mathrm{Co}$ CIGAL cell of CEA-Cadarache (DEVM/DSV); the activity of about $40000 \mathrm{Ci}$ allowed dose rates around $3 \mathrm{kGy} / \mathrm{h}$. 
Loss on drying was measured with an IR balance (Mettler LJ16 Moisture Analyzer). The loss on drying was performed during $50 \mathrm{~min}$ at $120^{\circ} \mathrm{C}$.

Grinding was carried out with a Dangoumau mill (Prolabo; Fig. 2), using a single ball having a vertical oscillating movement in a cylindrical pot. The pot and ball make a system linked by inertia in the absence of powder (or when the quantity of powder inside the pot is small) and submitted to sinusoidal strengths. The system has been well described by Dandurant [6]. In the case of resonance, the oscillation periods of the pot and of the ball are identical, and the rod is in quadrature with regard to the pot (Fig. 3). Kurbatov et al. [7] recently simulated the alternative dynamic movement of the ball inside the pot. They observed (Mizonov, private communication) that, if the results were in good agreement with the description made by Dandurant in the case of a low amount of powder, the movement of the ball could be strongly modified according to the amount of powder and depending on the geometry of the pot as well as on the frequency of the vibration. During this experimental work, $1.25-6 \mathrm{~g}$ of $\alpha$-lactose monohydrate was introduced in a $65-\mathrm{cm}^{3}$ pot which had a vertical alternating movement of 730 cycles per minute. In order to eliminate

BALL MOVEMENT

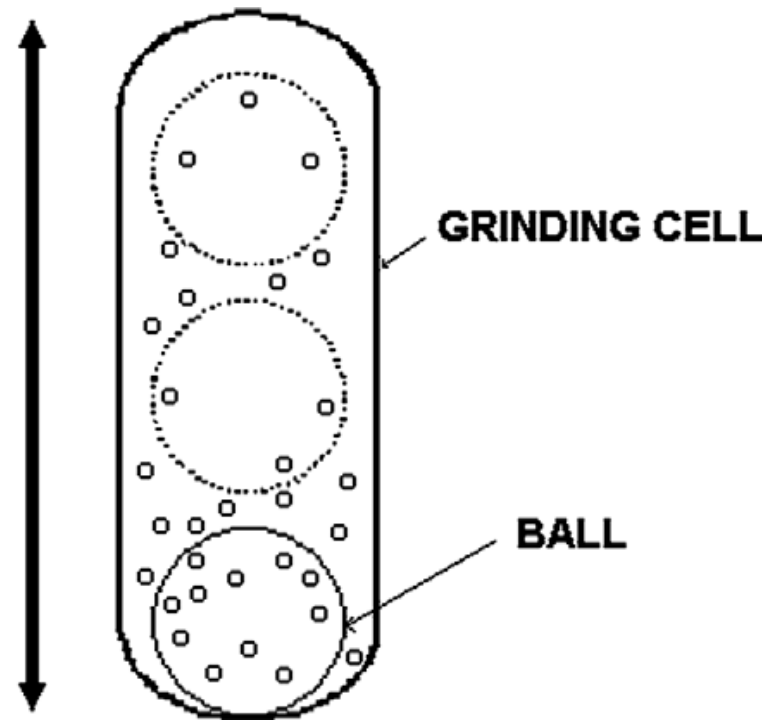

Figure 2. Schematic of the Dangoumau mill.

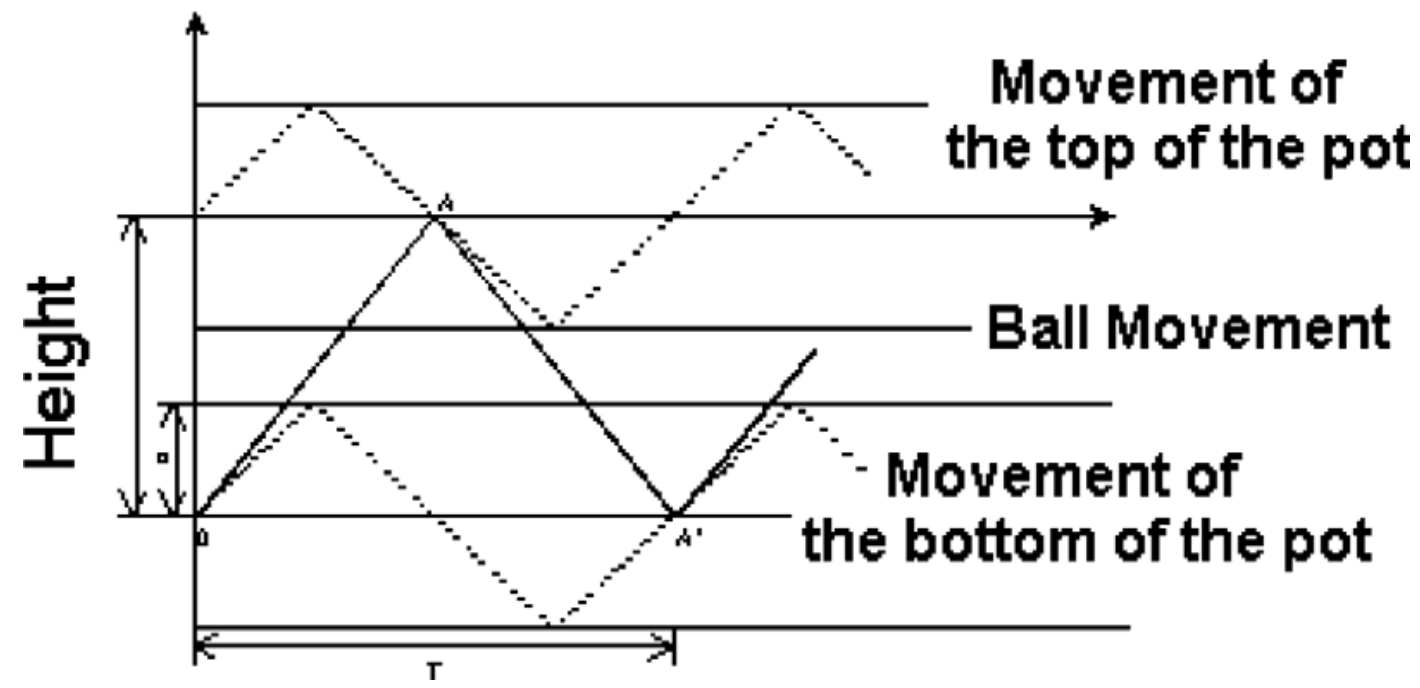

Figure 3. Modeling of the ball and pot movements in the Dangoumau mill. 
possible interference due to the physicochemical composition of the grinding media, we used balls of different materials; thus, grinding was performed using $20 \mathrm{~mm}$ diameter balls made of steel (30 g), zirconium (13 g) or aluminum (10 g).

\section{RESULTS AND DISCUSSION}

\subsection{Grinding of $\alpha$-lactose monohydrate}

In this section, we shall only discuss the relationship between the grinding parameters and the number of observed radicals. We make the usual approximation, which is that the number of radicals is proportional to the total intensity of the ESR signals (see, e.g. [8]).

Non-treated lactose samples present no signal. The ESR spectra of ground lactose are always weak (Fig. 4A) and require background baseline corrections (Fig. 4B). However, some general facts can be drawn from the variations of the ESR main line intensity (Tables 1-3):

- The number of radicals first increases with the grinding time and then is quite constant or even decreases. The maximum intensity is reached after grinding times of about 2 min for steel and 3.5 min for the other balls. This effect (i.e. a maximum or plateau) is probably due to a local increase of the temperature, leading to a slackening of the crystalline system links and to an increase of the water molecule mobility; consequently, a partial destruction occurs, with disappearance of the induced radicals. Using differential scanning calorimetry on lactose samples ground to different degrees, Irwin and Iqbal [9] showed that the molecule of water included in the crystal was gradually liberated during the grinding of $\alpha$-lactose monohydrate. We used an IR balance in order to follow the liberation of water during the grinding operation. It was found that the percentage of released water increased from 0.5 (no grinding) to about $4.5 \%$ (2 min) and is

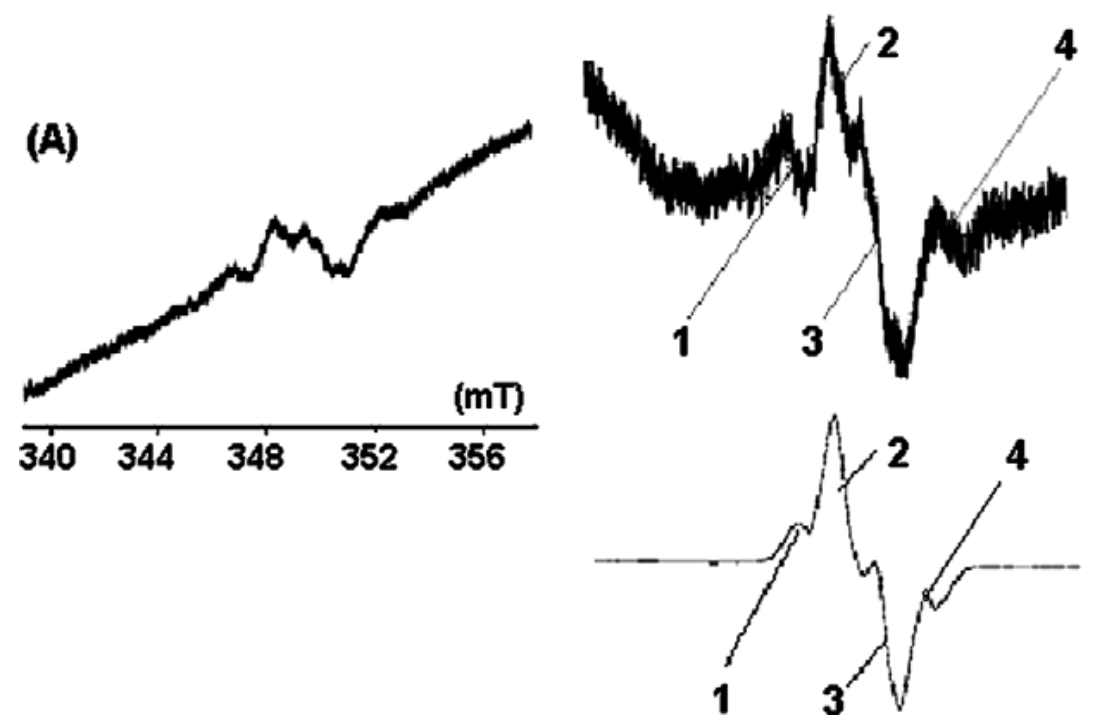

(B)

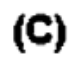

Figure 4. ESR spectra of radicals induced by grinding (A and B) or $\gamma$-radiation (C) in $\alpha$-lactose monohydrate; (B) is derived from (A) by correction of the base line. The field scale is the same for all the spectra, but the respective gains are 100, 500 and 1 for (A), (B) and (C). 
Table 1.

Number of radicals (arbitrary units) induced in lactose using a steel ball (ratio $=$ ball mass/powder mass)

\begin{tabular}{lll}
\hline Grinding time (min) & Ratio 5 & Ratio 8 \\
\hline 0.5 & 2.03 & 2.55 \\
1 & 2.25 & 2.64 \\
2 & 3.45 & 3.42 \\
5 & 3.19 & 1.77 \\
7 & 3.45 & 2.13 \\
10 & 3.32 & 1.93 \\
\hline
\end{tabular}

Table 2.

Number of radicals (arbitrary units) induced in lactose using a zirconium ball

\begin{tabular}{lll}
\hline Grinding time (min) & Ratio 5 & Ratio 8 \\
\hline 0.5 & 1.98 & 1.66 \\
1 & 1.89 & 2.45 \\
2 & 2.63 & 2.21 \\
5 & 1.87 & 2.82 \\
7 & 2.12 & 1.72 \\
10 & 1.77 & 1.53 \\
\hline
\end{tabular}

Table 3.

Number of radicals (arbitrary units) induced in lactose using an aluminum ball

\begin{tabular}{lll}
\hline Grinding time (min) & Ratio 5 & Ratio 8 \\
\hline 0.5 & 2.18 & 1.87 \\
1 & 1.63 & 1.98 \\
2 & 2.15 & 2.05 \\
5 & 3.15 & 1.63 \\
7 & 2.74 & 1.62 \\
10 & 1.83 & 1.64 \\
\hline
\end{tabular}

quite constant for grinding times up to $10 \mathrm{~min}$. This water, initially included in the crystal, gradually becomes more mobile because of crystal deformation and it was possible to eliminate it by heating the sample at $120^{\circ} \mathrm{C}$ for $50 \mathrm{~min}$. Its should be noted that $4.5 \%$ represents almost the total amount of water included in the crystal lattice $(5 \%)$.

- The number of radicals depends on the nature and mass of the balls; steel balls are more efficient than the other balls, the differences between the two other balls being not significant.

- The number of radicals depends on the 'ball mass/powder mass' ratio, the ratio 5 generally giving more radicals than the ratio 8, as shown in Fig. 5.

However, these preliminary experiments must be repeated again and again as grinding, a stochastic phenomena, is not totally reproducible. 


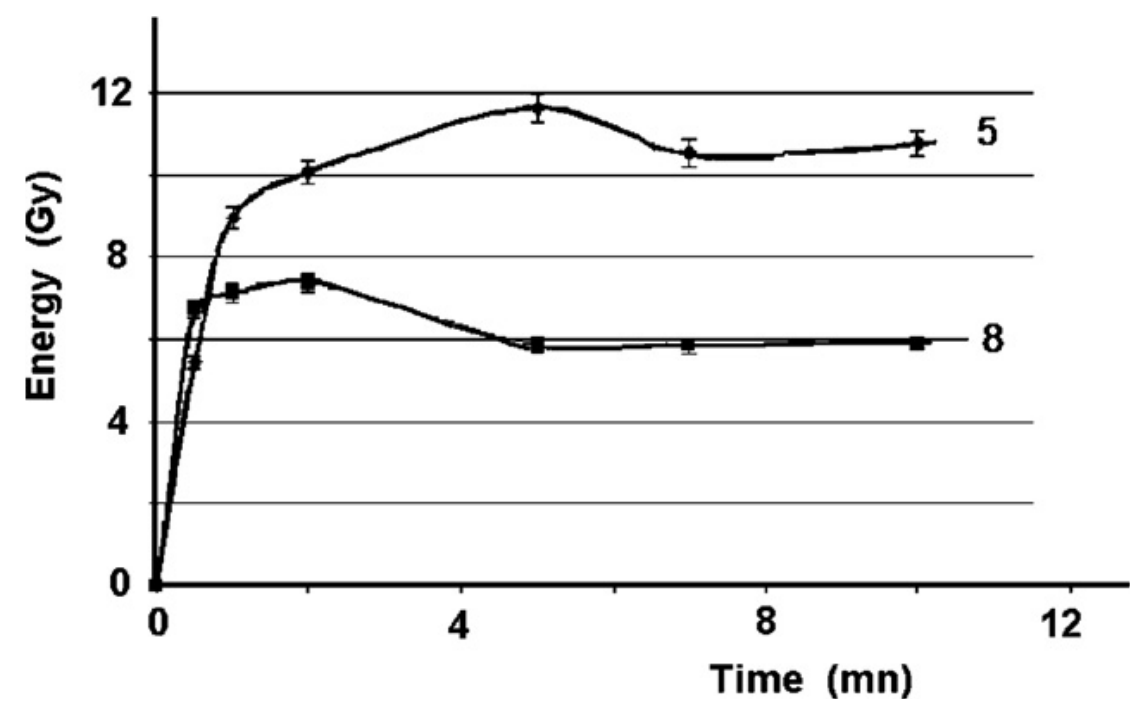

Figure 5. Number of radicals induced by lactose grinding with aluminum balls (the number indicates the value of the ball mass/powder mass ratio).

\subsection{Qualitative comparison with $\gamma$-irradiation of $\alpha$-lactose monohydrate}

Grinding always induces very small quantities of radicals. Thus, the observed spectrum (Fig. 4A) always requires a high gain, and has important noise and a nonhorizontal baseline which must be corrected (Fig. 4B). On the other hand, the ESR spectra of irradiated lactose (Fig. 4C) always show high intensities, low noise and do not require baseline corrections. However, in both cases, it is possible to distinguish four lines, or groups of lines, marked 1-4 in Fig. 4.

On all the recorded spectra, the line intensities of lines 2 and 3 are equal, and the horizontal distance between the two minima, on the one hand, and the two maxima, on the other hand, are constant. This leads us to think that lines 2 and 3 are relative, for both ground and irradiated samples, to the same radical 'R1', the spectrum of which is a doublet with a hyperfine constant:

'R1' $\Delta H=1.57 \mathrm{mT}$ and a $g$ factor around 2.005.

The problem is more complicated for lines 1 and 4 . The irradiated spectrum (Fig. 4C) clearly shows that line 4 is complex and there is also a doubt for line 1 where the maximum is very flattened. In the case of grinding, due to the noise, we only observe one 'doublet 1-4' for each spectrum. However, as ESR constants change with the grinding experiments, this leads us to think that there are in fact at least two different radicals ' $\mathrm{R} 2$ ' and 'R3' showing very close doublets for both the ground and irradiated samples. A compilation of the different spectra leads to the following constants:

'R2' $\Delta H=5.4 \mathrm{mT}$ and a $g$ factor around 2.004,

'R3' $\Delta H=5.7 \mathrm{mT}$ and a $g$ factor around 2.002.

It is very interesting to note that the same radicals are induced whatever the treatment, i.e. irradiation or grinding. The reason is probably due to the fact that, in each case, there is a statistical deposit of the energy on the different molecules and linkages, and consequently, the link breaks mainly correspond to the weakest 


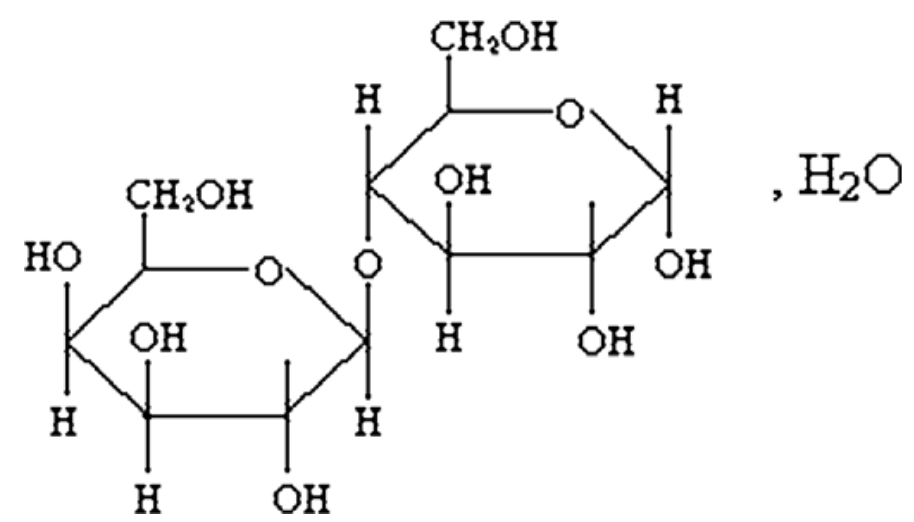

Figure 6. Chemical structure of $\alpha$-lactose monohydrate.

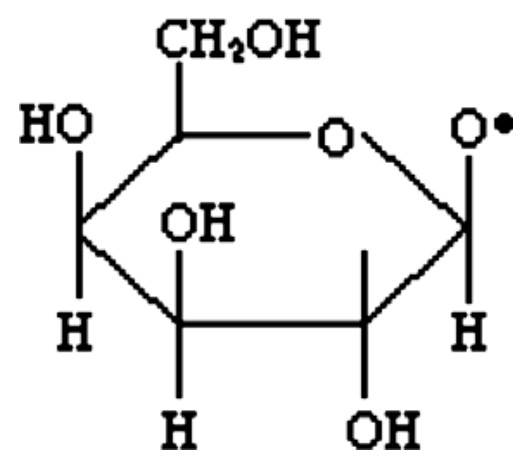

Figure 7. Representation of the main radical structure.

linkages. It is well known that the glycosidic linkage is one of the weakest ones [10-16], at least under $\gamma$-irradiation, and that the nature of the linkage [13-16] has no drastic influence on its scission. Thus, radical R1 is probably due to breakage between the two sugar rings of the lactose molecule (Fig. 6), as found elsewhere [15]. It must be noted that this radical is also induced by ultrasound [12], result confirming the more favorable breakage of the osidic linkage when energy is applied on lactose monohydrate. The structure of the major radical is represented in Fig. 7. Cases R2 and R3 are the most difficult; the high values of the hyperfine constants $(5.4$ and $5.7 \mathrm{mT})$ leads to a strong interaction with one proton; one opportunity is an $\mathrm{H}$ abstraction on carbons 6 and/or $6^{\prime}$ of the external $-\mathrm{CH}_{2} \mathrm{OH}$ groups outside the ring. Not stable in the case of sugar monomers (due to an internal rearrangement), this radical is mainly formed at low temperatures in disaccharides and oligomers, but is only present in low concentrations at room temperature [13-15]. As the ESR constants R2 and R3 are very close, it is possible to consider that we have:

- One radical in position 6 , the other one in position $6^{\prime}$, or

- The same chemical structure (only 6 or only $6^{\prime}$ position), but with two different crystalline environments in the solid matrices. 
- The quantity of radicals is relatively constant after the end of the grinding or irradiation treatments. In fact, on our samples we observed a small decrease of less than $2 \%$ of the ESR signal intensities during the first week of storage after treatment.

- The quantities of radical are proportional to the ESR line intensities [8].

- The minimum required energy to induce the same radicals is constant. The same method has already been used, e.g. to compare the radicals induced in starches by $\gamma$ - [16], UV [17] or cosmic [18] radiation.

If radicals are induced in the powder state, they are quite stable in the absence of water. In case of alanine, this phenomena was used as the basis of an international official method of the International Atomic Energy Agency [5] to determine the energy quantity deposited in the medium. The area of the double integration curve and the line intensity are proportional to the radical quantities, and allow a determination of the deposited energy, called the 'irradiation dose': a dose of $1 \mathrm{~Gy}$ corresponds to an absorption of an energy of $1 \mathrm{~J} / \mathrm{kg}$ of irradiated product.

With these hypotheses, the comparison of ESR intensities leads to a value of 9.8 Gy for the radicals induced by 2 min grinding with an aluminum ball.

In order to investigate and better understand the radical transformation obtained by the two different mechanisms, we compared the yields of the radical reaction obtained by irradiation as well as by mechanochemical treatments, as described below.

\subsubsection{Determination of the irradiation yield.}

3.3.1.1. Calculation of the solid angle used. As the source is irradiating toward all directions of the space, only a part of radiations will be able to irradiate the lactose. Thus, it is necessary to calculate the 'solid angle used', taking into consideration that:

- 'Cylinder 1', where the sample is located during irradiation, is centered $22 \mathrm{~cm}$ from the axis of the source.

- The surface exposed to radiation is around $1 \mathrm{~cm}^{2}$.

- The source is considered as punctual.

Using the classical formula:

$$
\Omega=2 \pi(1-\cos (\alpha)),
$$

with tangent $(\alpha)=1 / 22=0.04545$, then $\operatorname{cosinus}(\alpha)=0.99896$ and the calculated solid angle is:

$$
\Omega=2 \pi(1-\cos (\alpha))=6.48 \times 10^{-3} .
$$

3.3.1.2. Calculation of the irradiation yield $Y_{\mathrm{R}}$ (transformation of $\alpha$-lactose monohydrate to radicals by means of irradiation energy). During the irradiations, the source activity was around $40000 \mathrm{Ci}$, corresponding to $40000 \times 3.7 \times 10^{10}=$ 
Table 4.

Comparison of the radical yields obtained by $\gamma$-irradiation and mechanochemical treatment

\begin{tabular}{lll}
\hline & Gamma cell & Dangoumau mill \\
\hline Energy origin & ${ }^{60}$ Co & kinetic energy \\
Given energy $(\mathrm{J})$ & 3840 & 52740 \\
Absorbed energy $(\mathrm{J})$ & 0.833 & 9.8 \\
Yield (efficient/ total energy) & $Y_{\mathrm{R}}=2.2 \times 10^{-4}$ & $Y_{\mathrm{M}}=1.9 \times 10^{-4}$ \\
\hline
\end{tabular}

$1.48 \times 10^{15}$ disintegrations/s. For each disintegration, two photons are produced, having energies of 1.17 and $1.33 \mathrm{MeV}$ or $2.50 \mathrm{MeV}$ globally. Thus, each second, $\left(1.48 \times 10^{15}\right) \times 2.5=3.7 \times 10^{15} \mathrm{MeV}$ is 'sent to space'. As $1 \mathrm{MeV}$ is equal to $1.6 \times 10^{-13} \mathrm{~J}$, the energy sent to space is: $\left(3.7 \times 10^{15}\right) \times\left(1.6 \times 10^{-13}\right)=592 \mathrm{~J} / \mathrm{s}$. Thus, a $1 \mathrm{~cm}^{2}$ area, i.e. a solid angle of $6.48 \times 10^{-3}$, in theory receives an amount of energy of $592 \times\left(6.48 \times 10^{-3}\right)$, i.e. $3.84 \mathrm{~J}$. The same $1-\mathrm{cm}^{2}$ area corresponds to a sphere of $1 \mathrm{~cm}^{3}$, i.e. an approximate mass of $1 \mathrm{~g}$ (postulating that the density is about 1) which consequently receives $3.84 \mathrm{~J}$, i.e. $3840 \mathrm{~J} / \mathrm{kg} / \mathrm{s}$.

On another hand, the dose rate of the $\gamma$ cell is around $3 \mathrm{kGy} / \mathrm{h}$, or $0.8333 \mathrm{~Gy} / \mathrm{s}$, which means that $1 \mathrm{~kg}$ of matter put in Cylinder 1 receives an energy equal to $0.8333 \mathrm{~J}$. One gram will receive only $0.833 \times 10^{-3} \mathrm{~J}$, which means in comparison to the $3.84 \mathrm{~J}$ transported by the radiation, we obtain the following yield:

$$
Y_{\mathrm{R}}\left(E_{\text {received }} / E_{\text {cobalt }}\right)=2.17 \times 10^{-4} \approx 2 \times 10^{-4} .
$$

3.3.2. Calculation of the global mechanochemical yield $Y_{\mathrm{M}}$ (transformation of $\alpha$ lactose monohydrate to radicals by means of kinetical energy). Dandurant [6], taking the hypothesis that, with small quantities of powder inside the pot, the movement of the ball was not fundamentally modified, calculated that the kinetical energy given by one shock of the aluminum ball during a grinding operation with the same Dangoumau mill was equal to $E_{1}=0.072 \mathrm{~J}$. Taking into account the frequency of the mill (730 cycles/min), within 2 min (grinding time) the global amount of energy given to $2 \mathrm{~g}$ lactose with an aluminum ball is $0.072 \times 2 \times 730=$ $105.12 \mathrm{~J}$. For $1 \mathrm{~kg}$, it corresponds to $52704 \mathrm{~J}$. As the measurement of the ESR intensities after grinding $2 \mathrm{~g}$ leads, by comparison with $\gamma$-irradiated lactose, to an energy of $9.8 \mathrm{~J} / \mathrm{kg}$, in this case, the yield is:

$$
Y_{\mathrm{M}}=1.86 \times 10^{-4} \approx 2 \times 10^{-4} \text {. }
$$

\section{DISCUSSION}

Table 4 provides a summary of the radical yields from lactose produced by irradiation or mechanochemical reaction. It can be seen easy that a yield near to $2 \times 10^{-4}$ was calculated both for the global mechanochemical radical transformation $\left(Y_{\mathrm{M}}\right)$ as well as the radical transformation using irradiation $\left(Y_{\mathrm{R}}\right)$. As radiation is only 
poorly absorbed by water or organic products, this means that the mechanochemical radical yield is very low.

However, at the same time, similar yields for the formation of similar radicals by these different methods could corroborate the hypothesis of a statistical deposit of energy at the level of the molecules and bonds leading to the breakage of the weakest bonds.

Comparison of samples treated in the Dangoumau mill with irradiated samples allows quantification of mechanochemical radicals.

It should be noted that this energy is not only used to make the observed radicals, but also the radiolytic products due to the reactions of the not quite stable radicals. However, we make the hypothesis that for reactions producing the primary radicals, being mainly identical in the case of radiolysis or grinding mechanisms, the measurement of the concentration of 'final radicals' can lead to a good estimation of the energy efficiency, even for chemical compounds induced by mechanochemical reactions. However, we also make the hypothesis that, during $\gamma$ irradiation, virtually no energy is used to increase the product temperature. This approximation can be made as it is well known that during $\gamma$-sterilization of foodstuffs or drugs (i.e. using doses of 25-50 kGy) the temperature increase is less than $0.3-0.4^{\circ} \mathrm{C}$ [19]. However, in the case of grinding, we probably will have local increases of the temperature, but the short grinding time restricts any global increase of the powder temperature.

The mechanisms involved in the formation of radicals from lactose by irradiation and mechanochemistry are obviously different. In the case of irradiation, one photon can induce 4000-6000 successive irradiations, before the moment where the level of energy produced is comparable to the energetic level of the bond electrons. In the case of mechanochemistry, the energy is given to the powder globally, initiating compression, impact, shear stress, etc. With organic crystals, these actions can lead to fracture and dislocation beginning from defects. During these dislocations, molecules and molecular bonds can be deformed, inducing a closing of the HOMO-LUMO (highest occupied molecular orbital-lowest unoccupied molecular orbital) gap. By closing the electronic gaps, shear gives direct access of the bonding electrons to the antibonding states, so they become delocalized and can arrange at electronic frequencies, instead of being limited to atomic vibrational frequencies $[20,21]$.

\section{CONCLUDING REMARKS}

In this paper, we propose a novel concept, and present a new and flexible method to measure the energy involved in a mechanochemical reaction occurring during fine grinding. Under conditions where we could irradiate the same samples, a comparison between the ESR spectra recorded on samples where radicals are induced by mechanochemical reactions allows the determination of an 'equivalent $\gamma$-irradiation dose' on each treated sample. This allows further comparisons 
between different grinding treatments (grinding time, nature and size of the balls, types of grinders, etc.). This method is fast, applicable to different treatments (grinding, UV irradiation, natural or artificial ageing, etc.), even if mainly limited to solid and quite dry products stored at room temperature (or below). This original method gives an elegant solution to estimating the quantity of energy used during a mechanochemical reaction, by using a molecular probe located inside the material: we used the formation of an organic radical by a mechanochemical reaction as a probe to explore this grinding energy. Of course, the results could be compared to the levels of energy found by molecular dynamics [22]. However, such methods sometimes present limitations and it is not easy to apply them in the case of complex molecules included in a crystalline structure.

Potentially, a wide range of mechanochemical reactions and grinding systems can be used to measure the energy efficiency used during mechanochemical or fine grinding operations. The development of this kind of method is of course of theoretical importance, but can also potentially aid in the scaling-up of industrial processes, by comparing the efficiency of different kinds of mills.

According to our knowledge, this paper represents the first methodological approach in order to estimate the accurate energy efficiency used during a mechanochemical reaction in a fine grinding operation at the crystal or molecular level, where the investigation is not easy to perform.

One of our future goals will be to apply this method for measurement of energy during a mechanochemical process to aid the scale-up of mechanochemical as well as grinding processes. Furthermore, work is in progress in our team and in connection with other national and international research groups to find new simple, robust and reliable mechanochemical reactions acting as probes in order to evaluate the efficient mechanochemical energy used during a fine grinding process at the molecular level. We hope that detailed knowledge of this energy will be a new way to improve our understanding of the grinding processes and contribute to energy saving in these kind of processes, from a perspective of sustainable development.

\section{REFERENCES}

1. V. V. Boldyrev, Interrelation between fine grinding and mechanical activation, Int. J. Miner. Process. 44/45, 181-185 (1996).

2. J. Raffi, S. Gelly, L. Barral, F. Burger, P. Piccerelle, P. Prinderre, M. Baron and A. Chamayou, ESR study of radicals induced in drugs and relative products by different treatments, Spectrochim. Acta A 58, 1313-1320 (2002).

3. H. Rumpf, Physics aspects of comminution and new formulation of a law of comminution, Powder Technol. 7, 21-26 (1973).

4. D. Regulla, A. Bartolotta, U. Deffner, S. Onori, M. Pantaloni and A. Wieser, Calibration network based on alanine/ESR dosimetry, Appl. Radiat. Isotopes. 44, 23-31 (1993).

5. ISO/ASTM 51607 (2002).

6. J. L. Dandurant, Thesis, Université Paul Sabatier, Toulouse (1978). 
7. A. A. Kurbatov, V. Mizonov, M. Baron and A. Chamayou, Investigation of dynamic regimes of vibrating activator of fine powders, in: Proc. Methods of Cybernetics in Technologies, Economics, and Production Control, Ivanovo, pp. 12-15 (2002)

8. J. Wertz and J. Bolton, ESR: Elementary Theory and Practical Applications. McGraw-Hill, New York (1972).

9. W. J. Irwin and M. Iqbal, Solid-state stability: the effect of grinding solvated excipients, Int. J. Pharm. 75, 211-218 (1991).

10. M. Kuwabara, Y. Lion and P. Rieisz, ESR of spin-trapped radicals from sugars. Reactions of hydroxyl radicals in aqueous solutions and gamma-radiolysis in the polycrystalline state, Int. J. Radiat. Biol. 39, 451-455 (1981).

11. S. Adam, Recent developments in radiation chemistry of carbohydrates, in: Recent Advances in Food Irradiation, P. S. Elias and A. J. Cohen (Eds), pp. 149-170. Elsevier, Biomedical, Amsterdam (1983).

12. H. Heusinger, Comparaison of the reactions induced by ultrasounds and gamma rays in aqueous lactose solutions, Ultrasonics 28, 30-36 (1990).

13. J. Thiéry, C. Thiéry, J.-P. Agnel, P. Vincent, C. Battesti, J. Raffi and J. C. Evans, Gamma radiolysis of glucose oligomers: a spin-trapping study, Magn. Reson. Chem. 28, 594-600 (1990).

14. J. Triolet, C. Thiéry, J.-P. Agnel, C. Battesti, J. Raffi and P. Vincent, ESR spin trapping of gamma induced radicals in sucrose, Free Rad. Res. Commun. 10, 57-61 (1990).

15. C. Von Sonntag and M. Dizdaroglu, Radical chain reactions in crystalline $\alpha$-lactose monohydrate, Z. Naturforsch. 28b, 367-368 (1973).

16. J. Raffi and J.-P. Agnel, Influence of the physical structure of irradiated starches on their ESR spectra kinetics, J. Phys. Chem. 87, 2369-2373 (1983).

17. A. C. Bertolini, C. Mestres, P. Colonna and J. Raffi, Free radicals formation in the UV and gamma irradiated cassava starch, J. Carbohydr. Polym. 44, 269-271 (2001).

18. J. F. Bayonove, J. Raffi and J.-P. Agnel, Investigation on Rice Seeds and Emryos after the LDEF, ESR Identification, Adv. Space Res. 14, 1053-1057 (1994).

19. J. Raffi, The state of food irradiation and of detection of irradiated foodstuffs, Rec. Adv. Food Sci. 3, 11-19 (2002).

20. J. J. Gilman, Mechanism of shear-induced metallization, Czechoslov. J. Phys. 45, 913-919 (1995).

21. J. J. Gilman, Why silicon is hard, Science 261, 1436-1439 (1993).

22. K. Mizukami, F. Saito and M. Baron, Study on grinding of pharmaceutical products with an aid of computer simulation, in: Proc. Matériaux 2002, Tours, pp. 1-4 (2002). 